HETEROCYCLES, Vol. , No. , , pp. -. (c) The Japan Institute of Heterocyclic Chemistry

Received, ,Accepted, ,Published online, . COM-06-(Please do not delete.)

ONE-POT SYNTHESIS OF 6-SUBSTITUTED

\title{
AMINO-2,4-DIAMINOPYRIMIDINE DERIVATIVES USING KETENE DITHIOACETALS WITH AMINES AND GUANIDINE CARBONATE
}

\author{
Miki Hirose, ${ }^{\text {a }}$ Masayori Hagimori, ${ }^{\text {b }}$ Yasuhiro Shigemitsu, ${ }^{\mathrm{c}}$ Naoko \\ Mizuyama, ${ }^{\mathrm{d}}$ Bo-Cheng Wang, ${ }^{\mathrm{e}}$ and Yoshinori Tominaga ${ }^{\mathrm{a} *}$
}

${ }^{a}$ Faculty of Environmental Studies, Nagasaki University, 1-14, Bunkyo-machi, Nagasaki 852-8521; ${ }^{b}$ Faculty of Pharmaceutical Sciences, Nagasaki International University, 2825-7, Huis Ten Bosch Sasebo 859-3298; ' $T$ Technology Center of Nagasaki 2-1308-8, Ikeda, Omura Nagasaki 856-0026, Japan. ${ }^{\mathrm{d}}$ Department of Pharmacy, Saga University Hospital, 5-1-1, Nabeshima, Saga 849-8521; ${ }^{\mathrm{e}}$ Department of Chemistry, Tamkang University, Tamsui 251, Taiwan. E-mail: ytomi@nagasaki-u.ac.jp

\begin{abstract}
Substituted amino-2,4-diaminopyrimidine derivatives were prepared by one-pot synthesis using ketene dithioacetals, amine compounds, and guanidine carbonate in pyridine. These pyrimidine products displayed blue fluorescence in the solid state.
\end{abstract}

Appropriately functionalized ketene dithioacetals are versatile reagents that have been extensively utilized in heterocyclic synthesis. Ketene dithioacetals are readily prepared by condensation of active methylene compounds with carbon disulfide in an appropriate solvent in the presence of a base followed by methylation with dimethyl sulfate. ${ }^{1}$

Pyrimidine derivatives constitute a partial structure of purine bases and many biologically active compounds in living organisms. They have attracted much attention from the viewpoint of medicinal chemistry. ${ }^{2}$ The soporific and hypnotic barbiturates, as well as several antibacterial and antimalarial drugs, contain pyrimidine rings. ${ }^{3}$ It has been reported that the synthesis of pyrimidine derivatives is attained by the condensation reaction of ketene dithioacetals with amidine derivatives in the presence of an appropriate base. ${ }^{4}$ Pyrimidines obtained by this method leave one more methylsulfanyl group, but these pyrimidine derivatives are not used as an important potential precursor for directing various heterocycles owing to low activity. Displacing a methylsulfanyl group on the pyrimidine ring with nucleophilic 
reagents is difficult. To circumvent this problem, the first reaction should be by the reaction of ketene dithioacetals with amines, then with guanidine, and finally cyclization should be between a guanidinyl group and a cyano group.

Ketene dithioacetal (1a) ${ }^{5}$, benzylamine (2a) (as amine) and guanidine carbonate (4) were selected in a preliminary experiment. Ketene dithioacetal (1a) was allowed to react with benzylamine (2a) at room temperature without a solvent and a catalyst to give caramel oil (3a) in quantitative yield. On the other hand, the reaction of ketene dithioacetal (1a) with guanidine carbonate (4) under reflux conditions in pyridine gave 2,4-diamino-6-methylsulfanyl-5-carbonitrile (5) in 87\% yield (Scheme 1). ${ }^{4,6}$ Hence, we attempted to synthesize 6-substituted amino-2,4-diaminopyrimidine derivatives by one-pot reaction of ketene dithioacetals with amines and guanidine.<smiles>C[SH](C)(C)=C(C#N)C#N</smiles>

$1 \mathrm{a}$<smiles>CS(=O)(=O)C(C#N)=C(C#N)C#N</smiles>

$1 \mathrm{a}$<smiles>NCc1ccccc1</smiles>

$2 a$<smiles>N=C(N)N</smiles>

4<smiles>CSC(NCc1ccccc1)=C(C#N)C#N</smiles>

$3 a$<smiles>CSc1nc(N)nc(N)c1C#N</smiles>

5

\section{Scheme 1}

A mixture of ketene dithioacetal (1a; $10.0 \mathrm{mmol})$, benzylamine (2a; $11.0 \mathrm{mmol})$ and guanidine carbonate (4; $15.0 \mathrm{mmol}$ ) in $10 \mathrm{~mL}$ of pyridine was refluxed for $3 \mathrm{~h}$, and then $200 \mathrm{~mL}$ of water was added to yield the desired compound; pyrimidine derivative (6a). The crystallized precipitate from DMF was collected by filtration to give colorless needles, $\mathrm{mp} 187-188^{\circ} \mathrm{C}$, in $93 \%$ yield. Other 6 -subsituted amino-2,4-diaminopyrimidine-5-carbonitriles (6b-d) were readily obtained by a similar method (Table 1).

Next, 6-arylamino-2,4-diaminopyrimidine-5-carbonitriles $\mathbf{( 6 e - \mathbf { i } )}$ were synthesized using ketene dithioacetal (1a), substituted aniline (2e-i) and guanidine carbonate (4). Preparation of the intermediate 3-methylsulfanyl-3-arylamino-2-cyanoacrylonitriles (3e-i), which could be prepared by refluxing for 1-2 $\mathrm{h}$ in ethanol or by direct heating at $150-200^{\circ} \mathrm{C}$, was the key part of the reaction. After the reaction of $1 \mathrm{a}$ 
Table 1. Synthesis of 6-substituted amino-2,4-Diamino-6-alkylaminopyrmidine-5-carbonitriles ${ }^{\mathrm{a}}$

\begin{tabular}{|c|c|c|c|c|}
\hline 1a & 2a-d & 4 & & 6a-d \\
\hline & $\mathrm{NR}_{2}$ & Yield $\%$ b & $\mathrm{Mp}^{\circ} \mathrm{C}$ & Appearance (solvent) \\
\hline $6 \mathbf{a}$ & $\mathrm{NH}-\mathrm{CH}_{2}-\mathrm{C}_{6} \mathrm{H}_{5}$ & 93 & $187-188$ & colorless needles $(\mathrm{MeOH})$ \\
\hline b & $\mathrm{NH}-\mathrm{CH}(\mathrm{Me})-\mathrm{C}_{6} \mathrm{H}_{5}$ & 94 & $157-158$ & colorless needles (EtOH) \\
\hline c & & 70 & $228-229$ & colorless prisms $(\mathrm{MeOH})$ \\
\hline d & $\mathrm{N}$ & 85 & $259-260$ & colorless leaflets $(\mathrm{MeOH})$ \\
\hline
\end{tabular}

${ }^{\mathrm{a}} \mathbf{1 a}$ (1.0 equiv); $\mathbf{2}$ (1.1 equiv); 4 (3.0 equiv). ${ }^{\mathrm{b}}$ Isolated yield.

with arylamines (2e-i) under reflux conditions in pyridine for $1 \mathrm{~h}$, guanidine carbonate (4) was added to reaction mixture. This mixture was refluxed continuously for $3 \mathrm{~h}$ and then poured into $200 \mathrm{~mL}$ of water. Product (6e) was recrystallized from DMF to give colorless prisms, mp 263-264 ${ }^{\circ} \mathrm{C}$, in $73 \%$ yield. Compounds $(\mathbf{6 f}-\mathbf{i})$ were synthesized in a manner similar to that described for the preparation of $\mathbf{6 e}$ and yields are shown in Table 2.

Table 2. Synthesis of 6-arylamino-2,4-diamino-6-arylaminopyrmidine-5-carbonitriles ${ }^{\mathrm{a}}$

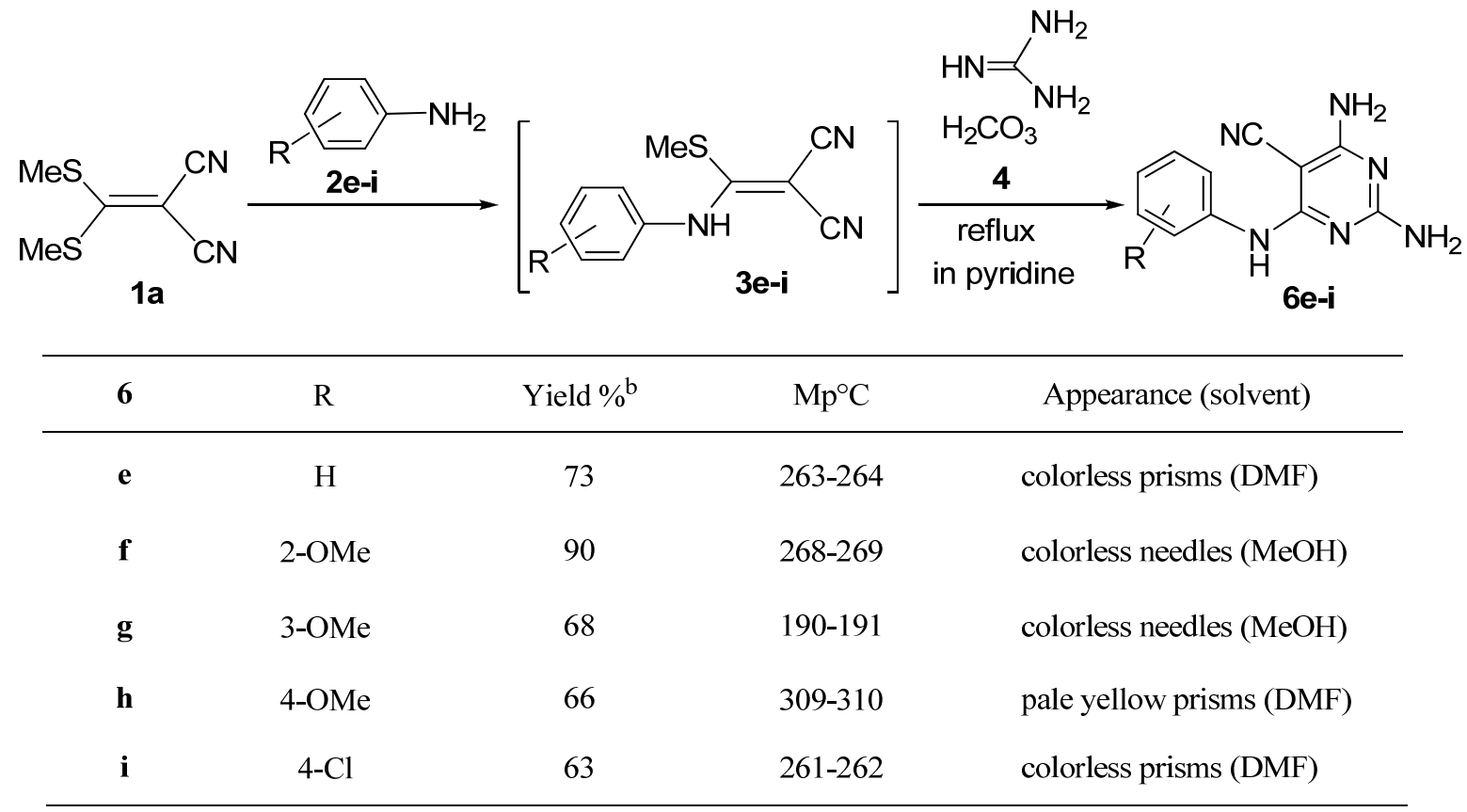

${ }^{\mathrm{a}} \mathbf{1} \mathbf{a}$ (1.0 equiv); 2 (1.1 equiv); 4 (3.0 equiv). ${ }^{\mathrm{b}}$ Isolated yield. 
Various pyrimidine derivatives (7-9) could be readily obtained from other ketene dithioacetals (except 1a) by this one-pot reaction (Scheme 2). Ketene dithioacetal $\mathbf{1 b}^{7}$ was allowed to react with benzylamine (2a) and guanidine carbonate (4) under reflux conditions in pyridine and then poured into $200 \mathrm{~mL}$ of water to give 2-amino-6-benzylamino-4-hydroxypyrimidine-5-carbonitrile (7) ${ }^{8}$ in $62 \%$ yield. In a similar manner, 2,4-diamino-6-benzylamino-5-phenylsulfonylpyrimidine (8) was synthesized from sulfonyl ketene dithioacetal (1c) ${ }^{9}$, 2a and 4 in 75\% yield. 2-Amino-4-benzylaminoindeno[2,1-d]pyrimidin-5-one (9) was also synthesized from $\alpha$-oxoketene dithioacetal (1d) ${ }^{10}$, benzylamine (2a) and $\mathbf{4}$ in $92 \%$ yield.

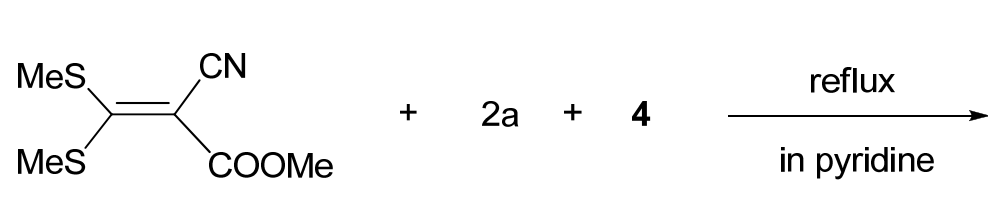

$1 \mathrm{~b}$<smiles>CS(=O)(=O)C(C#N)=C(C#N)S(=O)(=O)O</smiles>

$1 \mathrm{c}$<smiles>C[SiH3]C(C)=C1C(=O)c2ccccc2C1=O</smiles>

1d<smiles>N#Cc1c(O)nc(N)nc1NCc1ccccc1</smiles><smiles>Nc1nc(N)c(S(=O)(=O)c2ccccc2)c(NCc2ccccc2)n1</smiles>

8<smiles>Nc1nc(Nc2ccccc2)c2c(n1)-c1ccccc1C2=O</smiles>

9

\section{Scheme 2}

\section{FLUORESCENCE OF PYRIMIDINES}

The 6-substituted amino-2,4-diaminopyrimidine derivatives obtained were fluorescent materials; they emitted blue light in the solid state. Organic electron luminescent materials which show fluorescence in the solid state have been considerably interest because of their attractive characteristics and potential applications as next-generation display devices. Studies of 2-pyrone derivatives clarified that 6-aryl-2-pyrone derivatives having a phenylsulfonyl group showed stronger fluorescence than corresponding 2-pyrone-bearing cyano or ester groups at position $3 .^{11}$ The fluorescence of 6-substituted amino-2,4-diaminopyrimidine derivatives in the solid state was of considerable interest to our research group. $\mathrm{Alq}_{3}$ [tris(8-hydroxyquinolinato)aluminum] ${ }^{12}$ was used as a standard sample for fluorescence spectra. In general, the synthesized pyrimidine derivatives did not show strong fluorescence. However, in these derivatives,

the strongest

fluorescent compound was 
2,4-diamino-6-(2-methoxyphenyl)-pyrimidine-5-carbonitrile (6f), which emitted light 0.67-times that of $\mathrm{Alq}_{3}$ at $442 \mathrm{~nm}$ in the solid state. Evaluating of the structure-activity relationship with fluorescence intensity on the amino group at the 6 position in these pyrimidines is currently being conducted.

In conclusion, a new one-pot procedure for the synthesis of 6-substituted amino-2,4-diaminpyrimidines and fused pyrimidines (e.g., 9) using ketene dithioacetals, alkyl or aromatic amines, and guanidine carbonate in pyridine has been described. The notable advantages offered by this method are an environmentally friendly reaction that is easy to carry out, high yields of products, and cost effectiveness.

\section{REFERENCES AND NOTES}

1. (a) Y. Tominaga and Y. Matsuda, J. Heterocycl. Chem., 1985, 22, 937; (b) Y. Tominaga and Y. Matsuda, Yuki Gousei Kyoukaishi (J. Synth. Org. Chem. Japan), 1985, 43, 669; (c) Y. Tominaga, Yuki Gousei Kyoukaishi (J. Synth. Org. Chem. Japan), 1989, 47, 413; (d) Y. Tominaga, Trends in Heterocyclic Chemistry, 1991, 2, 43; (e) Y. Tominaga, Y. Shigemitsu and K. Sasaki, J. Heterocycl. Chem., 2002, 39, 571.

2. (a) R. L. Shriner and F. W. Newmann, Chem. Rev., 1944, 35, 351; (b) D. J. Brown, 'Pyrimidines and Their Benzo Derivatives in Comprehensive Heterocyclic Chemistry,' in Vol. 3, ed. by A. R. Katrizky and C. W. Rees, Pergamon Press, Oxford, 1984, p.57, p.443; (c) H. Yamanaka and T. Sakamoto, Yuki Gousei Kagaku Kyoukaishi (J. Synth. Org, Chem. Japan), 1985, 43, 951.

3. (a) F. A. El-Essay, N. R. El-Brollosy and E. B. Pedwesen, J. Heterocycl. Chem., 2003, 40, 213; (b) G. Wollein and R. Troschutz, J. Heterocycl. Chem., 2002, 39, 1195.

4. Y. Tominaga, S. Kohra, H. Honkawa and A. Hosomi, Hetrocycles, 1989, 29, 1409.

5. 1a: Y. Tominaga, J. K. Luo, L. W. Castle and R. N. Castle, J. Heterocycl. Chem., 1993, 30, 267.

6. Compound $\mathbf{6 a}$ was not obtained by the reaction of $\mathbf{5}$ with benzylamine.

7. 1b: R. Gompper and W. Toepfl, Chem. Ber., 1962, 95, 2861.

8. A. Kumar, V. Aggarwal, H. Ila and H. Junjappa, Synthesis, 1980, 748.

9. 1c: M. Augustin, R. Schmidt and W. D. Rudorf, Z. Chem., 1977, 17. 289.

10. 1d: M. Augustin, Ch. Groth, H. Kristen, K. Peseke and Ch. Wiehmann, J. Prakt. Chem., 1979, 320, 205.

11. N. Mizuyama, Y. Murakami, S. Kohra, K. Ueda, K. Hiraoka, J. Nagaoka, K. Takahashi, Y. Shigemitsu and Y. Tominaga, J. Heterocycl. Chem., 2007, 44, 115.

12. H. Odaka, Y. Okimoto, T. Yamada, H.Okamoto M. Kawasaki and Y. Tokuda, Appl. Phys Lett., 2006, 88123501. 